\title{
Time-dependent Reliability Analysis of Flood Defence Assets Using Generic Fragility Curve
}

\author{
Jaya Nepal ${ }^{1}$, Hua-Peng Chen ${ }^{2, a}$, Jonathan Simm $^{3}$ and Ben Gouldby ${ }^{3}$ \\ 1 School of Architecture, Computing and Engineering, University of East London, London, E16 2RD, UK \\ ${ }^{2}$ Department of Engineering Science, University of Greenwich, Chatham, Kent, ME4 4TB, UK \\ ${ }^{3}$ Flood Management Group, HR Wallingford, Oxfordshire, OX10 8BA, UK
}

\begin{abstract}
Flood defence assets such as earth embankments comprise the vital part of linear flood defences in many countries including the UK and protect inland from flooding. The risks of flooding are likely to increase in the future due to increasing pressure on land use, increasing rainfall events and rising sea level caused by climate change also affect aging flood defence assets. Therefore, it is important that the flood defence assets are maintained at a high level of safety and serviceability. The high costs associated with preserving these deteriorating flood defence assets and the limited funds available for their maintenance require the development of systematic approaches to ensure the sustainable flood-risk management system. The integration of realistic deterioration measurement and reliabilitybased performance assessment techniques has tremendous potential for structural safety and economic feasibility of flood defence assets. Therefore, the need for reliability-based performance assessment is evident. However, investigations on time-dependent reliability analysis of flood defence assets are limited. This paper presents a novel approach for time-dependent reliability analysis of flood defence assets. In the analysis, time-dependent fragility curve is developed by using the state-based stochastic deterioration model. The applicability of the proposed approach is then demonstrated with a case study.
\end{abstract}

\section{Introduction}

Flooding is a growing problem in the UK and worldwide. According to the article published in BBC the majority of the area in England and Wales will be under the worst case scenario of flood risk, as shown in Figure 1 and the cost associated with increased risk of flooding may rise by 20 -fold in 2080 . Recently, the problem was highlighted again due to severe flooding in 2015/16 winter, causing significant economic losses. Earth dykes, used as major flood defence structures in the UK, can become more vulnerable due to changing operation conditions during extreme events, as evidenced by the numerous breaches along earth embankments during the December 2013 East Coast surge event and the collapse of banks of River Ouse in December 2015. Hence, many existing earth embankments are currently under threat due to global warming induced sea level rises and increased sea storminess, which results in increased magnitude and frequency of hydrodynamic actions, larger overtopping flows, increased stresses within the structures and reduced resistance of the structure. Hence, in order to protect inland from flooding, it is of paramount importance that these flood defence structures are maintained at a high level of resilience and serviceability.

\footnotetext{
$\bar{a}$ Corresponding author: h.chen@gre.ac.uk
}

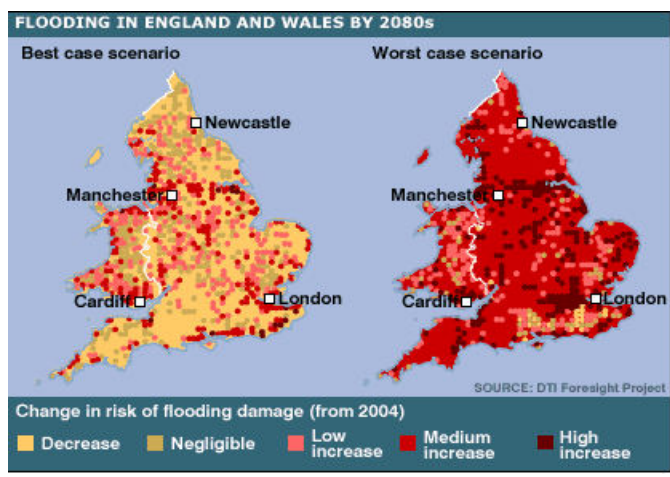

Figure 1. Risk of flooding in England and wales [1].

The prioritization of scarce resources required for the maintenance repair and rehabilitation of flood defence structures is a major problem in flood risk management. Effective flood risk management is important so that the country is in the best position to tackle risks, and to protect life and properties. Recent advances in lifecycle management, preventive maintenance strategies, reliability and optimization techniques could be the fundamentals for the strategic flood risk management. As these techniques will help in estimating the reliability of these deteriorating flood defence structures and making 
decision required for the optimal inspection and maintenance [2-6]. Therefore, for the effective flood risk management, the estimation of the likelihood of failure of the flood defence structures such as embankments under different hydraulic conditions with respect to their deterioration sate is essential. This paper presents a novel approach for time-dependent reliability analysis of embankments. In the analysis, time-dependent fragility curve is developed by using the state-based stochastic deterioration model. The applicability of the proposed approach is then demonstrated with a case study.

\section{Deterioration of embankment}

Earth embankments form the majority of linear flood defences in the UK, especially in rural or semirural areas. Embankments have been extensively studied with a wealth of research relating to them particularly when they are used to create a dam. An earth embankment can have a very long lifespan with many experts agreeing that its lifespan is infinite, given good local soil conditions and regular maintenance to ensure performance. Embankments are commonly subject to settlement over their lifespan due to the compaction of the underlying soils. Local geotechnical or hydrological processes can cause movement or deformation of the embankment which, if left unchecked or investigated, can lead to failure of the embankment through a number of mechanisms. Detailed information on deterioration of the embankment and associated failure modes can be found in Long et al. [7]. HR Wallingford's Performance \& Reliability study [8] on flood defence assets draws upon this work and includes a number of performance models relating to embankments that can be used to derive fragility curves.

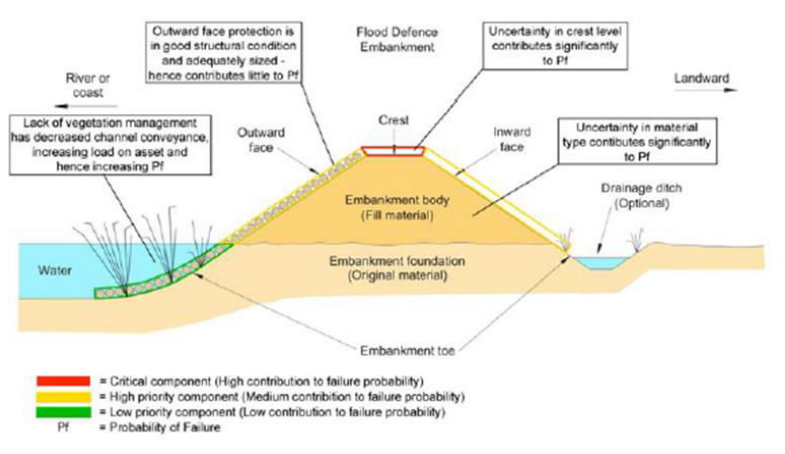

Figure 2. Potential performance deterioration of earth embankments (after [8]).

Using the historical data related to embankment performance and its failures, a new methodology based on performance based assessment has been proposed and has been adopted by the Environment Agency [2, 7, 9]. Figure 2 shows the potential performance deterioration of earth embankment. This methodology involves assessment of performance features, calculation of failure mode indices and finally the evaluation of the condition state of the assets. More details can be found in Long et al. [7]. The definition of the condition grade as defined by Environment Agency is given in Table 1. In Table 1, the five condition rates ( 1 to 5 ), ranging from "very good" to "very poor", are defined with specific descriptions to report the condition according to flood defence performance. In this grading system, Condition State 1 (CS1) denotes the best condition and CS5 represents the worst condition. The generic description of CS1 is that the assets are in good condition, and there may be presents of superficial damage but the damage does not affect the performance of the feature. The worst state CS5 denotes that the asset is no longer able to perform its function at even a reduced level.

\begin{tabular}{cll}
\hline Grade & Rating & \multicolumn{1}{c}{ Description } \\
\hline 1 & $\begin{array}{l}\text { Very } \\
\text { Good }\end{array}$ & $\begin{array}{l}\text { Cosmetic defects that will have no } \\
\text { effect on performance. }\end{array}$ \\
\hline 2 & Good & $\begin{array}{l}\text { Minor defects that will not reduce the } \\
\text { overall performance of the asset. }\end{array}$ \\
\hline 3 & Fair & $\begin{array}{l}\text { Defects that could reduce performance } \\
\text { of the asset. }\end{array}$ \\
\hline 5 & Poor & $\begin{array}{l}\text { Defects that would significantly } \\
\text { reduce the performance of the asset. } \\
\text { Further investigation needed. }\end{array}$ \\
\hline 5 & $\begin{array}{l}\text { Very } \\
\text { poor }\end{array}$ & $\begin{array}{l}\text { Severe defects resulting in complete } \\
\text { performance failure. }\end{array}$ \\
\hline
\end{tabular}

Table 1. Condition grades and descriptions adopted by the Environment Agency [12].

According to this performance based assessment method, the Environment Agency has recently published a deterioration database of various flood defence assets. These deterioration database are developed to be used to predict the progression of asset condition through the five condition grades with respect to time. This deterioration database is based on real data and information relating to deterioration processes of individual flood defence assets and consider different factors: material, environment and degree of maintenance. In this paper the deterioration database are obtained from HR Wallingford who is the industrial partner of this project.

The information on deterioration rates of flood defence assets is useful for asset management. However, the asset performance often deteriorates with uncertainties, due to the nature of uncertain loading conditions and material properties. Therefore, it is necessary to translate the deterministic deterioration rates into the probabilistic deterioration models, so that the performance deterioration can be used for undertaking time-dependent reliability analysis and determining risk cost optimised maintenance strategy [6].

\section{Methodology of assessing the risk}

As discussed earlier the deterioration of earth embankment is complex phenomenon, which represents the different chains of events leading to the failure of the embankment. Failure here is defined as the performance failure with respect its flood defence capacity. In a 
quantitative flood risk assessment, reliability theory is applied to calculate a probability of failure. Reliability theory describes the strength $R$ and loading $S$ of failure mode by means of limit sate equation [10],

$$
Z=R-S
$$

In equation (1), the embankment fails when loading exceeds the strength $(Z \leq 0)$. Though the design and asset management of flood defences requires detailed understanding of the failure mechanism, flood risk assessment currently relies on approximate description of strength and loading of flood defence assets. Therefore, a generic fragility curve is used in flood risk assessment. The generic fragility curves are derived using traditional reliability methods as shown in equation (1). The generic fragility curves have been developed through consideration of two failure mechanisms: 1) failure through piping, occurring where hydraulic pressure gradients arising from extreme fluvial water levels or sea levels, causes seepage through defences, leading to internal erosion, and 2) collapse and failure owing to rear face erosion of the defence from overtopping [2]. A FORM method was used for integration of the resistance variables over the failure region. As few data currently exist on the parameters of the limit state equations, their ranges and distribution functions have been assigned using expert judgement. The uncertainties introduced within the process are captured using upper and lower bound estimates (see Figure 3). A detail development of generic fragility curve is out of scope of this paper. In this paper a generic fragility curve of Humber estuary developed by HR Wallingford are used for the analysis.

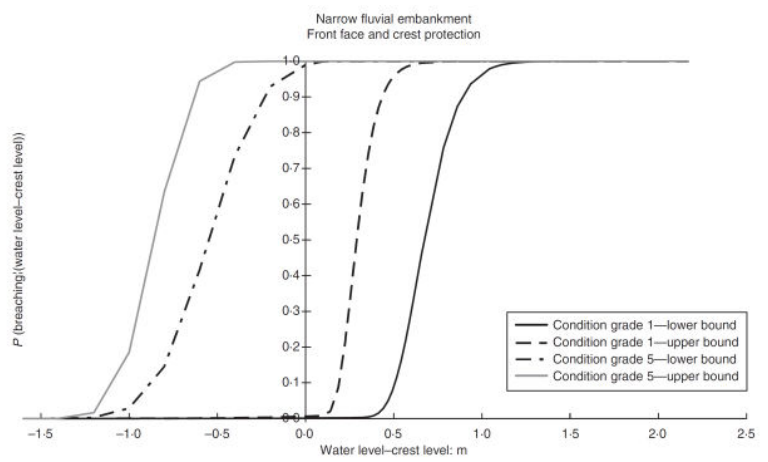

Figure 3. A generic fragility curves of earth embankments [2].

Similar to other civil engineering structure, the first step of the risk assessment of flood defence structures like embankment is to identify the vulnerability of the flood defence assets. Therefore, in order to measure the vulnerability associated with different state of deterioration, Markov chain model is used this paper, since this model can deal with the deterioration with uncertainties and gives the information of deterioration in stochastic nature.

Markov chain models are particularly suitable for state-based condition assessment and have been successfully implemented in bridge condition assessment e.g. PONTIS [11]. In a Markov process, the probability of transition to a future state, given the current state, is independent of the past states. For homogeneous Markov chains, the rate of transition from one state to another is constant over time. A change of state occurs only at the end of the time period and nothing happens during the chosen time period. The probability of moving from any given state $i$ to state $j$ on the next time interval is called the transition probability, $p_{i j}$. Considering five states condition state of embankment as defined in EA $[12,13]$, assuming that the embankment is not repaired as it deteriorates and the transition happens only between the subsequent states, the transition probability matrix $\boldsymbol{P}$ in Markov chain deterioration modelling can be expressed as $[6,14]$.

$$
\boldsymbol{P}=\left[\begin{array}{ccccc}
P_{11} & P_{12} & 0 & 0 & 0 \\
0 & P_{22} & P_{23} & 0 & 0 \\
0 & 0 & P_{33} & P_{34} & 0 \\
0 & 0 & 0 & P_{44} & P_{45} \\
0 & 0 & 0 & 0 & P_{55}
\end{array}\right]
$$

A transition probability matrix is fundamental part of Markov-chain model. The estimation of transition probabilities matrix required data from condition assessments of the existing structures. Therefore in this paper, condition deterioration data obtained from HR Wallingford will be used. Several methods like percentage prediction method, regression-based optimization method and non-linear optimisation techniques are frequently used in the estimation of transition probabilities matrix. In this paper transition probability matrix $\boldsymbol{P}$ for $n$ transitions is obtained by minimizing the difference between the observed and the predicted condition state of the flood defence assets, given as

$$
\text { Minimise: } \quad \sum_{t=T_{s}}^{t=T_{e}} \sum_{n=1}^{N}|\boldsymbol{O}(t)-\boldsymbol{E}(t)|
$$

$$
\begin{gathered}
\text { Subject to: } 0 \leq p_{i j} \leq 1, \text { for } i, j=1,2, . ., 5 \\
\qquad \sum_{j=1}^{5} p_{i j}=1, \text { for } i=1,2, . ., 5
\end{gathered}
$$

where $t$ is the age of the flood defence structure; $T_{s}$ and $T_{e}$ are starting and ending age for each zone of the asset, respectively; $N$ is the total number of transition periods in each zone; $\boldsymbol{O}(t)$ is the observed condition state at time $t$; and $\boldsymbol{E}(t)$ is the expected value of condition at time $t$ for $n$ transitions based on the Markov chain model. The difficulty associated with using mathematical optimization techniques in equation (3) is due to its nonlinear nature and can be solved by non-linear optimization techniques such as Evolutionary Algorithm (EA) and is adopted in this study. The expected condition rating $\boldsymbol{E}(t)$ is given by $\boldsymbol{E}(\mathrm{t})=\boldsymbol{C}^{(\mathrm{n})} \boldsymbol{S}^{\mathrm{T}}=\boldsymbol{C}^{(0)} \boldsymbol{P}^{(\mathrm{n})} \boldsymbol{S}^{\mathrm{T}}$ in which 
$\boldsymbol{C}^{(0)}$ is the initial condition state vector at year zero, by assuming that the newly constructed flood defence asset and its components are defect free and have a condition grade of 1 , which gives an initial condition state vector of $\boldsymbol{C}^{(0)}=\left[\begin{array}{lllll}0 & 0 & 0 & 0 & 0\end{array}\right]$, and $\boldsymbol{S}$ is the condition rating vector given by $S=\left[\begin{array}{lllll}1 & 2 & 3 & 4 & 5\end{array}\right]$.

\section{Case study}

Embankment of the Humber estuary (Figure 4) are now utilised to demonstrate the applicability of the statebased stochastic performance deterioration model in development of time dependent fragility curves. Therefore, in this section performance deterioration data of defence class 45 and generic fragility curve obtained from HR Wallingford as mentioned in Table 2 and Figure 5 , respectively, are used in the analysis.

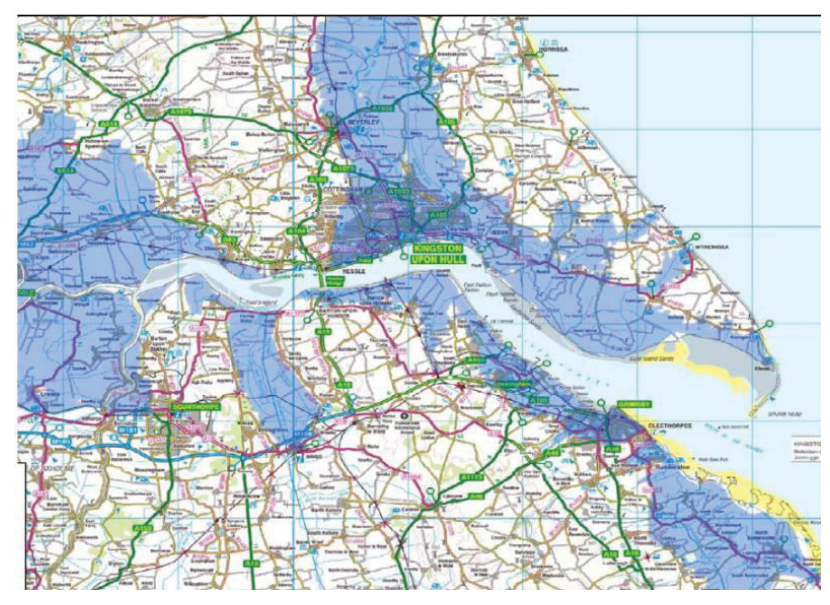

Figure 4. Humber Estuary Study location map [15].

\begin{tabular}{|l|l|l|l|l|l|}
\hline Condition states & $\mathbf{1}$ & $\mathbf{2}$ & $\mathbf{3}$ & $\mathbf{4}$ & $\mathbf{5}$ \\
\hline Age (years) & 0 & 3 & 6 & 25 & 40 \\
\hline
\end{tabular}

Table 2. Deterioration data of embankment

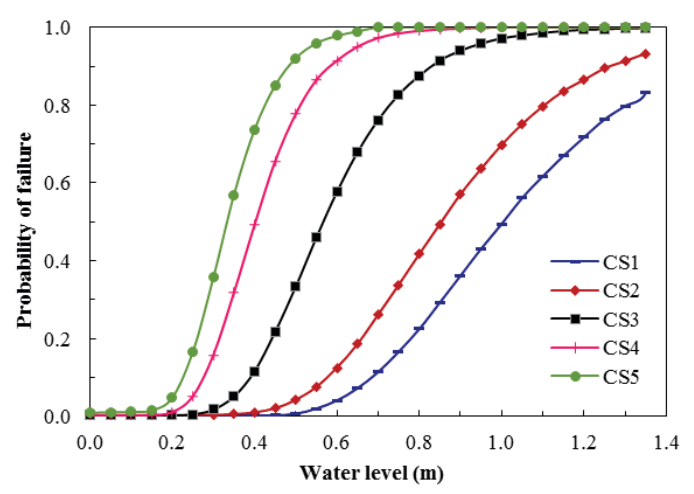

Figure 5. Generic fragility curves of embankment.
The proposed methodology of do-nothing scenario (i.e with no maintenance) is now applied to predict the state of the embankment over time and to evaluate the probability distribution of condition state from the associated deterioration rates. As mentioned earlier, the deterioration of the assets with progress of age is represented by five different condition states (1 to 5). A MATLAB code was developed for the proposed state based stochastic performance deterioration modelling, and nonlinear optimization based on evolutionary algorithm for the problem described in equation (3) was adopted in the iterative procedure until it converges to the actual condition state. Similar process was performed to evaluate the transition probability for each stage during the assets' life cycle. The estimated transition probability matrix for first stage of transition in case of no maintenance strategy as defined in equation (2) is given as

$$
\boldsymbol{P}^{(1)}=\left[\begin{array}{ccccc}
0.68 & 0.32 & 0 & 0 & 0 \\
0 & 0.78 & 0.22 & 0 & 0 \\
0 & 0 & 0.85 & 0.15 & 0 \\
0 & 0 & 0 & 0.69 & 0.31 \\
0 & 0 & 0 & 0 & 1.00
\end{array}\right]
$$

Based on the evaluated transition probability matrix, condition state distribution during the lifecycle of the structure concerned can be evaluated using the developed Markov chain model, as plotted in Figure 6. The results show how the embankment initially at condition state 1 (i.e. CS1) deteriorates from one state to another (CS1 to CS5) through the progress of time. From the results, it is clear that the probability of $\mathrm{CS} 1$ vanishes at approximately 20 years. CS3 has highest probability, compared with other condition states between the ages of 10 and 40 years. As expected, CS5 increases steadily with time, reaching approximately a probability of $70 \%$ at age of 40 years.

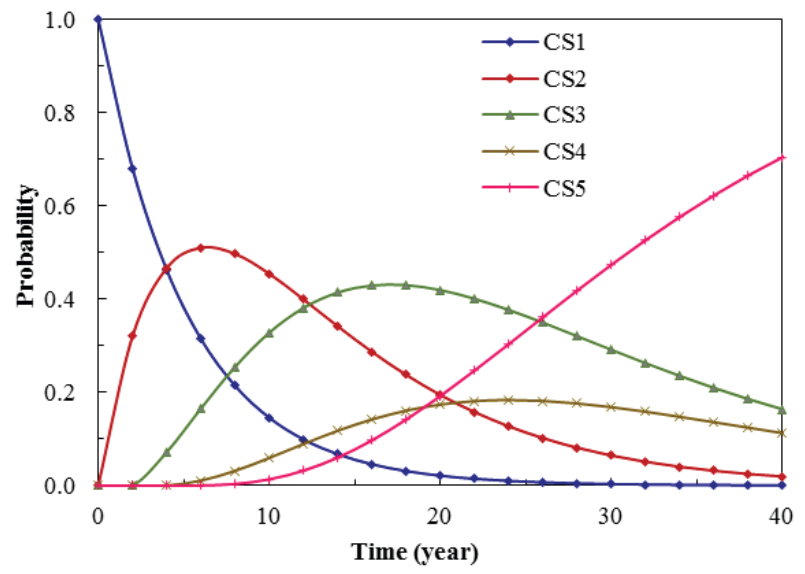

Figure 6. Condition state probability distribution over life time of earth embankment under no maintenance strategy. 
In order to validate the proposed methodology, Chisquare Goodness-of-fit test as used by Ranjith et al. [16] is utilised. The Goodness-of-fit test using Chi-squared test statistics, which is based on null hypothesis, is evaluated by using observed condition state and the estimated condition state by the Markov chain model. The evaluated values for the embankments are much less than the critical Chi-square value of 9.49 in this study, which validates the evaluation of condition states by using proposed state-based stochastic performance deterioration model.

By using the generic fragility curves shown in Figure 5, together with the obtained condition state probability distribution shown in Figure 6, the timedependent fragility curves are determined, as shown in Figures 7 and 8 . Figure 7 shows how the probability of failure of the embankment increases with time for particular water level represented by X.

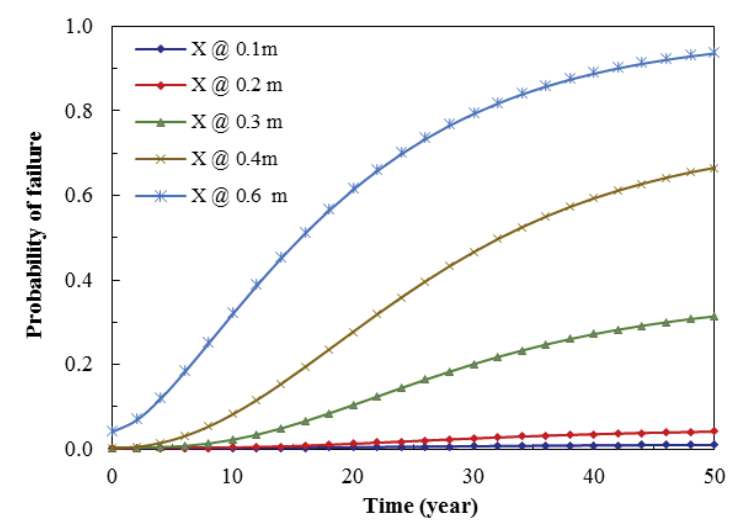

Figure 7. Time-dependent fragility curves for various water level.

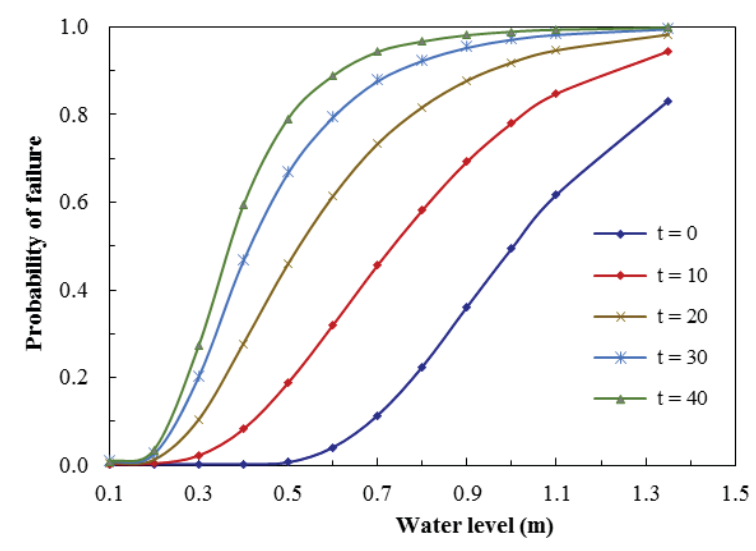

Figure 8. Time-dependent fragility curves at various given times.

Similarly, the trend of time-dependent probability of failure of the embankment with increasing water level for every 10 year interval starting from $t=0$ to $t=40$ years is presented in Figure 8. As expected the probability of failure of the embankment increase with both increase in time and water level. It is clear from the results, that the proposed methodology is capable of transferring deterministic deterioration model into timedependent fragility curve considering uncertainties associated with the embankment deterioration.

\section{Conclusions}

This paper presents a novel approach for timedependent reliability analysis of the embankment. In the analysis, the time-dependent fragility curve is developed by using the state-based stochastic deterioration model. The applicability of the proposed approach is then demonstrated with a case study of Humber estuary. At first a state-based stochastic deterioration model based on Markov chain was developed. By using the information from the state-based deterioration model in the generic fragility curve, a time-dependent fragility curve is developed. The developed time-dependent fragility curve is capable of giving the information related to the timedependent probability of failure of the embankment with rising water level.

On the basis of the results from the case study, the following conclusions are drawn: a) The deterministic asset deterioration model can be transferred to probabilistic performance deterioration models by using the proposed state-based stochastic modelling; b) The probability distribution of each condition states of the embankment over time can be obtained from state-based deterioration. The results obtained from the model show that the probability of good condition states continuously decreases with time, as expected; c) Time-dependent fragility curves are determined with consideration of stochastic performance deterioration. The developed time-dependent fragility curve of the embankment provides important information regarding the performance deterioration over time with uncertainties and the obtained information can be further used for determining the risk-cost based optimised maintenance strategy.

\section{Acknowledgement}

The authors are grateful for the financial support from the Natural Environment Research Council (Project No. NE/M008487/1) and the Institution of Civil Engineers through the R \& D Enabling Fund (Project No. 1305). The findings and opinions expressed in this study are those of the authors alone and are unnecessarily the views of the sponsors.

\section{References}

1. BBC News (2004). Flooding cost 'may rise 20-fold. $<$ http://news.bbc.co.uk/1/hi/uk/3648391.stm>.

2. Gouldby B., Sayers P., Mulet-Marti J., Hassan M.A.A.M. and Benwell D. (2008). A methodology for regional-scale flood risk assessment. Proceedings of the ICE - Water Management, 161(3), 169-182.

3. Buijs F., Gouldby B. and Sayers, P. (2006). Preliminary reliability analysis on the Thames 
Estuary: Dartford Creek to Gravesend, Report No. T07-06-07, Floodsite.

4. Buijs F.A., Hall J.W., Sayers P.B. and Van Gelder P.H. (2009). Time-dependent reliability analysis of flood defences. Reliability Engineering \& System Safety, 94(12), 1942-1953.

5. Chen H.P. and Alani A.M. (2012). Reliability and optimised maintenance for sea defences. Proceedings of the ICE - Maritime Engineering, 165(2), 51-64.

6. Nepal J., Chen H.P., Gouldby B., Simm J. and Tarrant, O. (2015). State-based stochastic performance deterioration modelling of flood defence assets. $7^{\text {th }}$ International Society for Structural Health Monitoring of Intelligent Infrastructure, Torino, Italy.

7. Long G., Mawdesley M. and Simm, J. (2008). Improved Approaches to Condition AssessmentVolume 2: Detailed Technical Report, FRMRC Research Report UR10. Flood Risk Management Research Consortium (FRMRC).

8. HR Wallingford (2004). Performance and Reliability of Flood and Coastal Defences, DEFRA/Environment Agency Flood and Coastal Defence R\&D Programme.

9. Long G., Mawdesley M. and Simm J. (2006). Improved Approaches to Condition AssessmentVolume 1: Performance-Based Visual Inspection of Flood Defence Assets, FRMRC Research Report UR10. Flood Risk Management Research Consortium (FRMRC).

10. Chen H.P. and Alan, A.M. (2013). Optimized maintenance strategy for concrete structures affected by cracking due to reinforcement corrosion, $A C I$ Structural Journal, 110(2), 229-238.

11. Saydam D., Frangopol D. and Dong Y. (2013). Assessment of risk using bridge element condition ratings. Journal of Infrastructure Systems, ASCE, 19(3), 252-265.

12. Environment Agency (2006). Managing Flood Risk Condition Assessment Manual. Reference 166_03_SD01, Environment Agency, Bristol, UK.

13. Environment Agency (2013). Delivering Benefits through Evidence - Practical guidance on determining asset deterioration and the use of condition grade deterioration curves: Revision 1. Reference SC060078/R1, Environment Agency, Bristol, UK.

14. Nepal J. and Chen H.P. Markov chain based stochastic deterioration modelling of repaired flood defence structures using evolutionary algorithm. $13^{\text {th }}$ International Probabilistic Workshop (IPW2015), Liverpool, 2015.

15. HR Wallingford5 (2011). Humber Estuary Study Final report. Wallingford, HR Wallingford.

16. Ranjith S., Setunge S., Gravina R. and Venkatesan S. (2013). Deterioration prediction of timber bridge elements using the Markov chain. Journal of Performance of Constructed Facilities, ASCE, 27(3), 319-325. 